\title{
Interaction of Anxiety, Depression and Hypertension on Quality of Life in Patients With Gynecological Tumor and the Moderating Effect of Social Support
}

Zhi-Hui Gu

China Medical University

Hui Wu ( $\nabla$ hwu@cmu.edu.cn )

School for Public Health,China Medical University https://orcid.org/0000-0002-4157-8023

\section{Research Article}

Keywords: quality of life, depression, anxiety, social support, hypertension, moderating effect

Posted Date: August 24th, 2021

DOI: https://doi.org/10.21203/rs.3.rs-812347/v1

License: (c) (1) This work is licensed under a Creative Commons Attribution 4.0 International License.

Read Full License 


\section{Abstract}

Objective: To explore the effect of anxiety, depression and hypertension on quality of life (QOL) of patients with gynecological tumor and the interaction among them, and the moderating effect of social support.

Methods: The study used the Self-Rating Anxiety Scale (SAS), the Self-Rating Depression Scale (SDS), the Functional Assessment of Cancer Therapy Genera tool (FACT-G), and the Multidimensional Scale of Perceived Social Support Scale (MSPSS). Regression analysis and the simple slope analysis were conducted.

Results: QOL of patients with anxiety and hypertension had seriously deteriorated [OR $=10.297,95 \% \mathrm{Cl}$ (5.647-18.775)]. And QOL of patients with depression and hypertension also had seriously deteriorated [OR=11.846, 95\% Cl (6.597-21.271)]. Calculated by crossover analysis, the synergy index, attributable proportion and relative excess risk due to interact of anxiety and hypertension were1.698,0.371 and 3.822, and the correlation index of interaction between depression and hypertension were 1.475, 0.295, and 3.493. The Social Support \&Depression interaction term and Social Support \&Anxiety interaction term were negatively correlated with QOL $(p<0.01)$, and explained an extra $5.7 \%$ and $5.6 \%$ of the variance respectively $(p<0.01)$.

Conclusion: Anxiety, depression and hypertension have interaction on the QOL of patients with gynecological tumors. Social support can significantly moderate the relationship between depression, anxiety and QOL respectively.

\section{Introduction}

Gynecological tumor is a common disease in women, including cervical cancer (the incidence rate ranked fourth in the world in 2018) [1], endometrial cancer (accounted for $7 \%$ of new cancer cases in American women in 2019) [2], ovarian cancer (the mortality rate was $21.6 \%$ in women) [3] and other malignant tumors. Because of the special disease track, loss of female characteristics after surgery, and accompanying symptoms of gynecological tumor, such as sexual health, fertility, and sexual desire problems, physiological and psychological problems are more prominent in the treatment process, affecting the quality of life (QOL) of patients [4-7]. QOL evaluation is an important outcome indicator of cancer research, reflecting the changes of physiological, social, psychological and emotional aspects of patients after illness [8]. Among the psychological factors affecting the QOL, cancer-related depression and anxiety are more common in the incidence of emotional disorders [9]. Research showed that more than $25 \%$ of cancer patients experienced depression or anxiety during the course of the disease [10]. The incidence of depression and anxiety in cancer patients was about $3.6 \%-57 \%[11]$ and $1.3 \%-23 \%$ respectively [12]. In many kinds of cancer patients, the anxiety level of female patients is significantly higher than that of male patients, and gynecological cancer patients are one of the highest anxiety groups $[13,14]$. While there was no difference in gender in depressive level [15]. Studies have found that 
the psychological status of patients can affect the progress and prognosis of tumor [16]. A meta-analysis showed that anxiety and depression affect $10 \%$ and $20 \%$ of cancer patients respectively at any stage of cancer [17]. About $75 \%$ of patients with obvious depression and anxiety did not receive any psychological or drug-related treatment systematically or never [18], leading to the obstruction of anti-cancer decisionmaking, poor treatment compliance, prolonged disease recovery time, and the QOL [19]. According to relevant research, about $34 \%-44 \%$ of cancer patients have obvious psychological stress reaction or psychological disorder, especially depression and anxiety, which affects the coping style, treatment compliance, immune function, and reduces the QOL [20].

In cancer patients, the most common cardiovascular disease is hypertension. Hypertension can affect the QOL of the elderly population, and has a greater impact on elderly women [21]. This showed that the problem of hypertension in patients with gynecological tumor can not be ignored. Epidemiological studies showed that the incidence rate of hypertension and depression is more than $4.95 \%$ [22]. A survey in Ghana found that $56.0 \%$ of hypertensive patients had anxiety symptoms [23]. In the United States, an epidemiological survey on 168630 patients with hypertension found that $4.3 \%$ of them had anxiety and 8.4\% had depression [24]. The effects of depression, anxiety and hypertension on QOL have been confirmed separately, however, few studies have discussed the interaction effect of them on the QOL of gynecological cancer patients. For patients with depression, anxiety and hypertension coexisting, it is inevitable that their QOL will be affected. Among them, hypertension can be treated by drugs, diet, lifestyle and so on, while for patients with depression and anxiety, in order to balance the impact of stressful life events, some studies have emphasized the importance of social support on the QOL of patients with mental illness [25]. Social support refers to the spiritual or material help and support system given by the outside world, and a good social support system helps to promote mental health [26]. Huang et al. found that social support was a moderator of depression on QOL in breast cancer patients, which can significantly alleviate the impact of depression on QOL [27]. While Panayiotou et al. found that social support helps, but does not buffer the negative impact of anxiety disorders on QOL in anxiety disorders participants [28]. Anyway social support directly and indirectly regulates the influence of variables to play its role, that is, the "buffer hypothesis", which has been widely confirmed [29]. Therefore, this paper chose social support as the moderating variable.

The purposes of this study are as follows: 1) This study analyzed the effect of depression, anxiety, the interaction of depression and hypertension, and the interaction of anxiety and hypertension on the QOL.

2) For patients with depression and anxiety, it also aims to test whether the social support could moderate the relationship between depression, anxiety and the QOL of gynecological cancer patients, and to provide the theoretical basis for improving the QOL of gynecological cancer patients.

\section{Methods}

\section{Study Design and Sample}


Since December 2019 to July 2020, the COVID-19 outbreak phase, more than 700 patients with gynecological cancer have been collected from the hospitals, and a total of 695 patients were collected finally. Inclusion criteria: during the investigation, the condition was relatively stable, with clear consciousness and no serious complications; voluntary participants; the expected survival time was $>9$ months.

\section{Assessment of Anxiety symptoms}

Zung's Self-Rating Anxiety Scale (SAS) was used [30]. The SAS considered both emotional and physical symptoms, including 20 items, of which 15 were negative experiences and 5 were positive experiences. Add all the items together to form a rough score, which is multiplied by 1.25 and rounded to get the standard score to evaluate anxiety. The index score of 45 (original score $=36$ ) was set as the cut-off point for clinical significant anxiety in our study [31]. The Cronbach's alpha of it was 0.918 in this study.

\section{Assessment of Depressive symptoms}

Zung's Self-Rating Depression Scale (SDS) was used [30]. The SDS also considered both emotional and physical symptoms, including 20 items, of which 10 were negative experiences and 10 were positive experiences. Add all the items together to form a rough score, which is multiplied by 1.25 and rounded to get the standard score to evaluate anxiety. The index score of 50 (original score $=41$ ) was set as the cutoff point for clinical significant depression in our study [32]. The Cronbach's alpha of it was 0.921 in this study.

\section{Assessment of Quality of Life}

The Functional Assessment of Cancer Therapy Genera (FACT-G) tool is applicable to all cancer sites, and is included as the common cancer core questionnaire for specific instruments of each fact cancer site [33]. The FACT-G is a cancer-targeted QOL measure that includes physical well-being, social well-being, emotional well-being, and functional well-being. The scale consists of 27 items with a total score range of 0 to 108 . In this study, the Cronbach's alpha of global scale was 0.899 .

\section{Assessment of Perceived Social Support}

The Multidimensional Scale of Perceived Social Support (MSPSS) was used to assess perceived social support as perceived by the respondents from family, friends and significant others [34]. The MSPSS is a subjective assessment of social support adequacy with 12-item. In this study, the Cronbach's alpha of global scale was 0.963 .

\section{Data analysis}

SPSS Statistics 21.0 software was used for statistical analysis. Chi square test was used to compare the count data. The significant variables in univariate analysis were used as independent variables, and multiple linear regression was performed. By using Delta method, the excel table compiled by Andersson et al. [35] was introduced to calculate the related indexes of interaction, and the $\beta 1, \beta 2,(\beta 1+\beta 2+\beta 3)$ and 
the variance and covariance between factors in logistic regression analysis were input into it. The OR value obtained by logistic regression model in the interaction calculation process was used as the estimation value of relative risk (RR). Interaction index: (1) the relative excess risk due to interact (RERI) was used to evaluate the difference between the combined effect of factor $A$ and factor $B$ and the sum of factors $A$ and $B$ alone; (2) the attributable proportion due to interaction (AP) was used to evaluate the proportion of interaction between two factors when two factors A and B exist at the same time; (3) the synergy index (S): when the interaction does not exist, the confidence interval of RERI and AP should contain 0 , and the confidence interval of $S$ should include [36-38]. Correlations among variables were examined by Pearson's correlation. Hierarchical regression analysis was used to prove the relationship of variables and to examine the moderating effect. Finally, the simple slope analysis was conducted to visualize the interaction term [39]. Significance level was $a=0.05$, and a two-tailed $P<0.05$ was considered to have statistical significance.

\section{Results}

\section{Basic information}

695 cases were investigated with an average age of $(56.50 \pm 9.86)$ years. The average score of quality of life was $71.12 \pm 17.91$. There were 344 cases with good quality of life $(>71.12)$ and 351 cases with poor quality of life( $\leq 71.12) .387$ cases had depression, and 356 cases had anxiety. The difference of quality of life between the two groups was statistically significant $(p<0.01)$. 90 patients had depression with hypertension, and 83 patients had anxiety with hypertension. The details are shown in Table 1. 
Table 1

Comparison of basic conditions of patients with different quality of life $(\mathrm{N}=695)$

\begin{tabular}{|c|c|c|c|c|}
\hline \multirow[t]{2}{*}{ Variables } & \multicolumn{2}{|c|}{ Quality of Life } & \multirow[t]{2}{*}{$x^{2}$} & \multirow[t]{2}{*}{$P$} \\
\hline & Good & Bad & & \\
\hline Age (Years) & $57.14 \pm 9.40$ & $55.87 \pm 10.27$ & 53.578 & 0.739 \\
\hline \multicolumn{5}{|l|}{ Marital status } \\
\hline Married/cohabited & 37 & 28 & 1.582 & 0.241 \\
\hline Single /separated & 307 & 323 & & \\
\hline \multicolumn{5}{|l|}{ Education level } \\
\hline Junior high school and below & 187 & 231 & 9.525 & $<0.001$ \\
\hline High/Technical secondary school & 137 & 104 & & \\
\hline Bachelor degree or above & 20 & 16 & & \\
\hline \multicolumn{5}{|l|}{ Monthly income (RMB) } \\
\hline$<2000$ & 84 & 82 & 5.846 & 0.054 \\
\hline $2000-4000$ & 178 & 209 & & \\
\hline$>4000$ & 82 & 60 & & \\
\hline \multicolumn{5}{|l|}{ Habitation } \\
\hline Rural & 113 & 96 & 2.498 & 0.117 \\
\hline Urban & 231 & 255 & & \\
\hline \multicolumn{5}{|l|}{ Hypertension } \\
\hline No & 261 & 264 & 0.041 & 0.860 \\
\hline Yes & 83 & 87 & & \\
\hline \multicolumn{5}{|l|}{ Diagnosis and treatment } \\
\hline Initial treatment & 302 & 306 & 0.059 & 0.820 \\
\hline Re-treatment & 42 & 45 & & \\
\hline \multicolumn{5}{|l|}{ Stage of cancer } \\
\hline Q & 182 & 163 & 5.049 & 0.080 \\
\hline$\square$ & 70 & 96 & & \\
\hline$\rrbracket+\square$ & 92 & 92 & & \\
\hline BMI & & & & \\
\hline
\end{tabular}




\begin{tabular}{|lllll|}
\hline Variables & \multicolumn{2}{l}{ Quality of Life } & \multirow{2}{*}{$\chi^{2}$} & $\boldsymbol{P}$ \\
\cline { 2 - 3 } & Good & Bad & & \\
\hline$<24$ & 198 & 189 & 0.970 & 0.360 \\
\hline$\geq 24$ & 146 & 162 & & \\
\hline Depressive symptoms & & & & \\
\hline No & 239 & 69 & 174.732 & $<0.001$ \\
\hline Yes & 105 & 282 & & \\
\hline Anxiety symptoms & & & & \\
\hline No & 249 & 90 & 151.925 & $<0.001$ \\
\hline Yes & 95 & 261 & & \\
\hline
\end{tabular}

\section{Multivariate logistic regression analysis of quality of life in patients}

In Table 2, taking the total score of quality of life as dependent variables, education level, depressive symptoms, and anxiety symptoms ( $p<0.01)$ and monthly income (RMB), habitation, and stage of cancer $(p<0.15)$ were included in the equation for multiple linear stepwise regression. The results showed that there were three factors in the equation: monthly income (RMB), depression and anxiety. After adjusting for monthly income (RMB), the risk of poor quality of life of depressed patients was higher than that of non depressed patients $(\mathrm{OR}=5.634,95 \% \mathrm{Cl}$ : $3.397-9.343)$, and the risk of poor quality of life was increased in anxiety group compared with non anxiety group $(\mathrm{OR}=2.644,95 \% \mathrm{Cl}: 1.613-4.336)$.

Table 2

Multiple linear regression analysis of quality of life

\begin{tabular}{|lllllll|}
\hline Factors & B & S.E. & Wald $\chi 2$ & $P$ & OR & $95 \% \mathrm{Cl}$ \\
\hline Monthly income (RMB) & & & & & & \\
\hline$<2000$ & & & & & & 1 (reference) \\
\hline $2000-4000$ & 1.117 & 0.281 & 15.841 & $<0.001$ & 3.054 & $1.762-5.293$ \\
\hline$>4000$ & 1.066 & 0.236 & 20.337 & $<0.001$ & 2.905 & $1.827-4.617$ \\
\hline Depressive symptoms & 1.729 & 0.258 & 44.872 & $<0.001$ & 5.634 & $3.397-9.343$ \\
\hline Anxiety symptoms & 0.972 & 0.252 & 14.863 & $<0.001$ & 2.644 & $1.613-4.336$ \\
\hline Constant & -2.309 & 0.257 & 80.785 & $<0.001$ & 0.099 & \\
\hline
\end{tabular}


As shown in Table 3, the reference is no depression and no hypertension. The OR value of non depression with hypertension on quality of life was 0.913 (95\% Cl: $0.492-1.695)$; the OR value of depression without hypertension on quality of life was 8.442 (95\%Cl: 5.666-12.578); the OR value of depression with hypertension on quality of life was 11.846 (95\% Cl: 6.597-21.271). The confidence interval of RERI and AP was greater than 0 , and the confidence interval of $S$ was greater than 1 , which indicated that depression and hypertension had additive interaction on the occurrence of poor quality of life in patients with gynecological tumor (this was a synergistic effect). AP was 0.295 , indicating that $29.5 \%$ of the patients with poor quality of life due to the interaction between depression and hypertension. We can also draw the conclusion that the $\mathrm{OR}$ value of non anxiety with hypertension on quality of life was 0.844 (95\% Cl: $0.480-1.483)$; the OR value of anxiety without hypertension on quality of life was 6.630 (95\%Cl: 4.527-9.711); the OR value of anxiety with hypertension on quality of life was 10.297 (95\%Cl: 5.64718.775). Anxiety and hypertension had additive interaction on the occurrence of poor quality of life in patients with gynecological tumor (this was a synergistic effect). $37.1 \%(A P=0.371$ ) of the patients with poor quality of life due to the interaction between anxiety and hypertension. 
Table 3

Risk analysis of depression/anxiety, hypertension and their interaction with quality of life

\begin{tabular}{|c|c|c|c|c|c|c|}
\hline \multirow[t]{2}{*}{ Depression } & \multirow[t]{2}{*}{ Hypertension } & \multicolumn{2}{|c|}{ Quality of Life } & \multirow[t]{2}{*}{ B } & \multirow[t]{2}{*}{$\mathbf{P}$} & \multirow[t]{2}{*}{ OR/RR(95\%Cl) } \\
\hline & & $\begin{array}{l}\text { Good } \\
\text { (344) }\end{array}$ & $\begin{array}{l}\text { Bad } \\
(351)\end{array}$ & & & \\
\hline - & - & 176 & 52 & - & & 1.00 (reference) \\
\hline- & + & 63 & 17 & -0.091 & 0.774 & $0.913(0.492-1.695)$ \\
\hline+ & - & 85 & 212 & 2.133 & $<.001$ & $8.442(5.666-12.578)$ \\
\hline+ & + & 20 & 70 & 2.472 & $<.001$ & $\begin{array}{l}11.846(6.597- \\
21.271)\end{array}$ \\
\hline RERI & & & & & & $3.493(2.832-9.818)$ \\
\hline AP & & & & & & $0.295(0.102-0.692)$ \\
\hline S & & & & & & $1.475(0.793-2.745)$ \\
\hline Anxiety & Hypertension & & & & & \\
\hline- & - & 183 & 69 & - & & 1.00 (reference) \\
\hline- & + & 66 & 21 & -0.170 & 0.555 & $0.844(0.480-1.483)$ \\
\hline+ & - & 78 & 195 & 1.892 & $<.001$ & $6.630(4.527-9.711)$ \\
\hline+ & + & 17 & 66 & 2.332 & $\begin{array}{l}< \\
0.001\end{array}$ & $\begin{array}{l}10.297(5.647- \\
18.775)\end{array}$ \\
\hline RERI & & & & & & $3.822(0.323-7.967)$ \\
\hline AP & & & & & & $0.371(0.087-0.655)$ \\
\hline S & & & & & & $1.698(1.013-2.845)$ \\
\hline
\end{tabular}

\section{Correlations among continuous variables}

As shown in Table 4, depressive symptoms and anxiety symptoms were negatively correlated with quality of life $(r=-0.422,-0.388, p<0.01)$ and perceived social support $(r=-0.538,-0.503, p<0.01)$. Perceived social support was positively correlated with quality of life $(r=0.514, p<0.01)$. 
Table 4

Correlations among study variables

\begin{tabular}{|c|c|c|c|c|c|c|}
\hline \multirow[t]{2}{*}{ Variables } & \multicolumn{2}{|l|}{ SDS } & \multicolumn{2}{|l|}{ SAS } & \multicolumn{2}{|l|}{ PSS } \\
\hline & $\mathbf{r}$ & $p$ & $\mathbf{r}$ & $p$ & $r$ & $p$ \\
\hline QOL & -0.422 & $<0.01$ & -0.388 & $<0.01$ & 0.514 & $<0.01$ \\
\hline PSS & -0.538 & $<0.01$ & -0.503 & $<0.01$ & 1.000 & - \\
\hline
\end{tabular}

\section{Hierarchical regression analysis}

As shown in Table 5, age and monthly income (RMB) were added in the first step. In the second block, depression, anxiety and perceived social support (PSS) were added respectively. Finally, the PSS\&Depression interaction term and the PSS\&Anxiety interaction term were added in the last block respectively. The PSS\&Depression interaction term was negatively correlated with quality of life $(\beta=-0.241, p<0.01)$, and explained an extra $5.7 \%$ of the variance $\left(F=68.649\right.$, adjusted $R^{2}=0.369, \Delta R^{2}=$ $0.050, p<0.01)$. The PSS\&Anxiety interaction term was negatively correlated with quality of life $(\beta=-0.235$, $p<0.01)$, and explained an extra $5.6 \%$ of the variance $\left(F=65.813\right.$, adjusted $R^{2}=0.359, \Delta R^{2}=0.048, p<$ 0.01 ). 
Table 5

Hierarchical linear regression for depression/anxiety and PSS with quality of life

\begin{tabular}{|c|c|c|c|c|c|c|}
\hline \multirow[t]{2}{*}{ Variables } & \multicolumn{3}{|c|}{ Quality of Life (Depression) } & \multicolumn{3}{|c|}{ Quality of Life (Anxiety) } \\
\hline & Block 1 & Block 2 & Block 3 & Block 1 & Block 2 & Block 3 \\
\hline Age & 0.019 & -0.010 & -0.020 & 0.019 & 0.003 & -0.020 \\
\hline \multicolumn{7}{|l|}{ Monthly income (RMB) } \\
\hline Dummy_1 & -0.016 & -0.014 & -0.015 & -0.016 & -0.017 & -0.006 \\
\hline Dummy_2 & 0.076 & $0.175^{\star \star}$ & $0.111^{\star \star}$ & 0.076 & $0.175^{\star \star}$ & $0.117^{\star \star}$ \\
\hline Depression & & $-0.262^{\star \star}$ & $-0.274^{\star \star}$ & & $-0.232^{\star \star}$ & $-0.266^{\star \star}$ \\
\hline PSS & & $0.388^{\star \star}$ & $0.308^{* \star}$ & & $0.413^{\star \star}$ & $0.338^{* \star}$ \\
\hline PSS\&Depression/PSS\&Anxiety & & & $-0.241^{\star \star}$ & & & $-0.235^{\star \star}$ \\
\hline $\mathrm{F}$ & 1.777 & $66.446^{* *}$ & $68.649^{\star *}$ & 1.777 & $64.244^{\star \star}$ & $65.813^{\star \star}$ \\
\hline Adjusted $\mathrm{R}^{2}$ & 0.003 & $0.320^{\star *}$ & $0.369^{* \star}$ & 0.003 & $0.313^{\star \star}$ & $0.359^{* \star}$ \\
\hline$\Delta \mathrm{R}^{2}$ & 0.008 & $0.318^{\star \star}$ & $0.057^{\star \star}$ & 0.008 & $0.310^{* *}$ & $0.056^{\star *}$ \\
\hline
\end{tabular}

\section{Simple slope analysis}

In Fig. 1, simple slope analysis showed that the association between depression and quality of life was gradually decreased in the mean $(B=-0.274, \beta=-0.237, p<0.01)$ and high $(+1$ SD above the mean, $B=-0.654, \beta=-0.565, p<0.01)$ groups of perceived social support. The results showed that low perceived social support ( -1 SD below the mean, $B=0.106, \beta=0.092, p>0.05$ ) was no statistical significance. It also showed that the association between anxiety and quality of life was gradually decreased in the low $(-1 \mathrm{SD}$ below the mean, $B=0.110, \beta=0.093, p<0.05)$, mean $(B=-0.269, \beta=-0.229, p<0.01)$ and high (+ 1SD above the mean, $B=-0.648, \beta=-0.552, p<0.01$ ) groups of perceived social support.

\section{Discussion}

The results showed that anxiety and depression were the influencing factors of quality of life. Foreign scholars also pointed out that depression, anxiety and other emotions have a stronger impact on psychological level than physical function [40]. Patients with gynecological tumor do not understand the disease and treatment, leading to more anxiety. Anxiety can reduce the quality of life by affecting physical function [41, 42]. For cancer patients, depression can aggravate the side effects of cancer treatment, affect the therapeutic effect, and even promote the recurrence and metastasis of tumor [43]. 
Therefore, anxiety and depression are risk factors of quality of life in patients with gynecological tumor. This study showed that hypertension had no effect on quality of life, which was different from previous studies [44], it may be caused by different populations or other unknown factors. However, hypertension and anxiety or hypertension and depression had additive interaction on the quality of life. The effect of two factors at the same time is greater than that of single factor. Carroll et al. found that the patients with anxiety and depression were significantly correlated with the incidence of hypertension [45]. Hamer et al. also found that anxiety and depression patients are more likely to cause varying degrees of blood pressure rise [46]. At present, many studies also suggested that hypertension itself may lead to anxiety and depression [47]. Research showed that in patients receiving anti-hypertensive treatment, 3/4 of them suffer from long-term illness, and most of them have anxiety and depression [48]. Hypertension will cause depression, anxiety, cognitive impairment, physical discomfort and sleep disorders. On the contrary, this psychological state will aggravate the condition of hypertension, resulting in a vicious circle between hypertension and anxiety, depression, which affected the prognosis of the disease, caused serious physical and mental consequences, and reduced the quality of life of patients.

In this study, anxiety and depression were negatively correlated with PSS, and PSS was positively correlated with quality of life, consistent with previous findings $[49,50]$. PSS moderates the effects of anxiety or depression on quality of life of patients. Social support can be used as an individual and internal resource to cope with and adapt to stress situations, enabling people to explain and deal with cancer, difficulties, hope and rehabilitation [29]. Studies have confirmed that social support was strongly positively correlated with the physiological and psychological aspects of long-term survival of cancer [51, 52]. Hence, social support is an important factor to predict the quality of life of cancer patients [50]. The key factor of social support as a stress buffer is that the individual perceives that others will provide appropriate support, which will reduce the emotional and physiological reactions of individual stress. This can explain why the more social support patients feel during treatment, the more beneficial it is to improve depression and anxiety symptoms [53]. Study also showed that only when social support is needed can social support buffer the symptoms of anxiety and depression in cancer patients [54]. This can explain why lower social support is not obvious in alleviating the relationship between depression, anxiety and quality of life in our study. Social support is associated with reduced cancer-related stress and depression symptoms, positive psycho-social changes, and lower mortality [51, 52, 55]. Based on the above theory, it is concluded that when patients have depression or anxiety, social support has a positive effect on improving the quality of life, reducing the possibility of depression or anxiety, thus changing the relationship between depression or anxiety and quality of life.

\section{Strengths and limitations}

First, compared with similar studies, the number of participants in this study is more than 700 . Second, we investigated depression, anxiety, hypertension and quality of life, and analyzed the influence of their interaction on quality of life. Finally, a complex adjustment model based on the concept of social support is also used. Social support helps to explain the relationship between depression and anxiety and quality of life by regulating the model, which provides evidence for the mechanism of social support regulating 
depression and anxiety disorder. This study is a cross-sectional study, so we can not get the causal relationship between variables. The effect of confounding factors was not taken into account, and the conclusion may be biased. In the future, we will continue to do longitudinal research on the samples involved, and consider more factors.

\section{Conclusion}

Depression, anxiety, hypertension and anxiety, and hypertension and depression have harmful effects on the quality of life, and the effect of two factors at the same time is greater than that of single factor. Perceived social support moderated the effects of anxiety or depression on quality of life of patients with gynecological tumor. We should improve their social support level to prevent poor quality of life.

\section{Declarations}

\section{Ethics approval and consent to participate}

The study protocol was in accordance with the ethical standards and was approved by the Ethics Committee of China Medical University (ChiCTR2000040122). All the participants agreed to take part in the study. Written informed consent was obtained from each participant. Information collected from all participants was kept confidential and anonymous.

\section{Availability of data and materials}

The datasets generated and/or analysed during the current study are not publicly available due to the protection of individual privacy of participants. However, these and the methodological tools used may be made available from the corresponding author on reasonable request.

\section{Competing interests}

The authors declare that they have no conflict of interest.

\section{Funding}

National Key R\&D Program of China (Grant \#2018YFC1311600).

\section{Author Contributions}

Z.H.G completed analysis and interpretation of data, statistical analysis, and writing of manuscript. H. W put forward study concept and design. All authors had full access to all data in the study and take responsibility for the integrity of the data and the accuracy of the data analysis.

\section{Acknowledgments}


The author would like to thank the teachers who helped me in this study, the doctors and students in the hospital who assisted in the investigation, and all the cancer patients and their families who cooperated in the investigation.

\section{References}

1. Bray F, Ferlay J, Soerjomataram I, Siegel RL, Torre LA, Jemal A. Global cancer statistics 2018: GLOBOCAN estimates of incidence and mortality worldwide for 36 cancers in 185 countries. CA Cancer J Clin. 2018; 68: 394-424. doi:10.3322/caac.21492.

2. Siegel RL, Miller KD, Jemal A. Cancer statistics, 2019. CA Cancer J Clin. 2019; 69: 7-34. doi:10.3322/caac. 21551

3. Chen W, Zheng R, Baade PD, Zhang S, Zeng H, Bray F, et al. Cancer statistics in China, 2015. CA Cancer J Clin. 2016; 66; 115-32. doi:10.3322/caac.21338.

4. Joly F, Hilpert F, Okamoto A, Stuart G, Ochiai K, Friedlander M. Fifth Ovarian Cancer Consensus Conference of the Gynecologic Cancer InterGroup: Recommendations on incorporating patientreported outcomes in clinical trials in epithelial ovarian cancer. Eur J Cancer. 2017; 78: 133-138. doi:10.1016/j.ejca. 2017.03.019.

5. Koster EB, Baars EW, Delnoij DM. Patient-centered outcomes on quality of life and anthroposophic healthcare: a qualitative triangulation study. Qual Life Res. 2016; 25: 2257-2267. doi:10.1007/s11136-016-1276-8.

6. Westin SN, Sun CC, Tung CS, Lacour RA, Meyer LA, Urbauer DL, et al. Survivors of gynecologic malignancies: impact of treatment on health and well-being. J Cancer Surviv. 2016; 10: 261-70. doi: 10.1007/s11764-015-0472-9.

7. Barnaś E, Skręt-Magierło J, Skręt A, Bidziński M. The quality of life of women treated for cervical cancer. Eur J Oncol Nurs. 2012; 16: 59-63. doi:10.1016/j.ejon.2011.03.001.

8. Pulgar Á, Alcalá A, Reyes Del Paso, GA. Psychosocial predictors of quality of life in hematological cancer. Behav Med. 2015; 41: 1-8. doi: 10.1080/08964289.2013.833083.

9. Bail JR, Traeger L, Pirl WF, Bakitas MA. Psychological Symptoms in Advanced Cancer. Semin Oncol Nurs. 2018; 34: 241-251. doi: 10.1016/j.soncn.2018.06.005.

10. Vodermaier A, Linden W, MacKenzie R, Greig D, Marshall C. Disease stage predicts post-diagnosis anxiety and depression only in some types of cancer. Br J Cancer. 2011; 105: 1814-7. doi: 10.1038/bjc.2011.503.

11. Kelly K, Posternak M, Alpert JE. Toward achieving optimal response: understanding and managing antidepressant side effects. Dialogues Clin Neurosci. 2008; 10: 409-18. doi:10.31887/ DCNS.2008.10.4/kkelly.

12. Brown LF, Kroenke K, Theobald DE, Wu J, Tu W. The association of depression and anxiety with health-related quality of life in cancer patients with depression and/or pain. Psychooncology. 2010; 19: 734-41. doi: 10.1002/pon.1627. 
13. Pitman A, Suleman S, Hyde N, Hodgkiss A. Depression and anxiety in patients with cancer. BMJ.2018; 361: k1415. doi: 10.1136/bmj.k1415.

14. Linden W, Vodermaier A, Mackenzie R, Greig D. Anxiety and depression after cancer diagnosis: prevalence rates by cancer type, gender, and age. Journal Of Affective Disorders.2012; 141: 343351.doi: 10.1016/j.jad.2012.03.025.

15. Miller S, Lo C, Gagliese L, Hales S, Rydall A, Zimmermann C, et al. Patterns of depression in cancer patients: an indirect test of gender-specific vulnerabilities to depression. Soc Psychiatry Psychiatr Epidemiol. 2011; 46: 767-74. doi: 10.1007/s00127-010-0246-7.

16. Borji M, Nourmohammadi H, Otaghi M, Salimi AH, Tarjoman A. Positive Effects of Cognitive Behavioral Therapy on Depression, Anxiety and Stress of Family Caregivers of Patients with Prostate Cancer: A Randomized Clinical Trial. Asian Pac J Cancer Prev. 2017;18: 3207-3212. doi: 10.22034/APJCP.2017.18.12.3207

17. Mitchell AJ, Chan M, Bhatti H, Halton M, Grassi L, Johansen C, et al. Prevalence of depression, anxiety, and adjustment disorder in oncological, haematological, and palliative-care settings: a metaanalysis of 94 interview-based studies. Lancet Oncol. 2011; 12: 160-74. doi:10. 1016/S14702045(11)70002-X.

18. Pascoe S, Edelman S, Kidman A. Prevalence of psychological distress and use of support services by cancer patients at Sydney hospitals. Aust N Z J Psychiatry. 2000; 34: 785-91. doi:10. 1080/j.14401614.2000.00817.x.

19. Murphy MJ, Newby JM, Butow P, Kirsten L, Allison K, Loughnan S, et al. Correction to: i Can ADAPT early protocol: randomised controlled trial (RCT) of clinician supervised transdiagnostic internetdelivered cognitive behaviour therapy (iCBT) for depression and/or anxiety in early stage cancer survivors -vs- treatment as usual. BMC Cancer. 2017; 17: 667. doi: 10.1186/s12885-017-3655-0.

20. He Y, Jian H, Yan M, Zhu J, Li G, Lou VWQ, et al. Coping, mood and health-related quality of life: a cross-sectional study in Chinese patients with advanced lung cancer. BMJ Open.2019; 9: e023672. doi: 10.1136/bmjopen-2018-023672.

21. Hajian-Tilaki K, Heidari B, Hajian-Tilaki A. Solitary and combined negative influences of diabetes, obesity and hypertension on health-related quality of life of elderly individuals: A population-based cross-sectional study. Diabetes Metab Syndr. 2016; 10: S37-42. doi:10. 1016/j.dsx.2016.01.018.

22. Le Roux S, Lotter GA, Steyn HS, Malan L. Cultural coping as a risk for depression and hypertension: the SABPA prospective study. Cardiovasc J Afr. 2018; 29: 366-373. doi:10.5830/CVJ A-2018-045.

23. Kretchy IA, Owusu-Daaku FT, Danquah SA. Mental health in hypertension: assessing symptoms of anxiety, depression and stress on anti-hypertensive medication adherence. Int J Ment Health Syst. 2014; 8: 25. doi: 10.1186/1752-4458-8-25.

24. Byrd JB, Powers JD, Magid DJ, Tavel HM, Schmittdiel JA, O'Connor PJ, et al. Detection and recognition of hypertension in anxious and depressed patients. J Hypertens.2012; 30: 2293-8. doi: 10.1097/HJH.0b013e328359b6e6. 
25. Goldberg RW, Rollins AL, Lehman AF. Social network correlates among people with psychiatric disabilities. Psychiatr Rehabil J.2003; 26: 393-402. doi: 10.2975/26.2003.393.402.

26. Brailovskaia J, Schönfeld P, Zhang XC, Bieda A, Kochetkov Y, Margraf J. A Cross-Cultural Study in Germany, Russia, and China: Are Resilient and Social Supported Students Protected Against Depression, Anxiety, and Stress? Psychol Rep. 2018; 121: 265-281. doi:10.1177/00332 94117727745.

27. Huang $\mathrm{CY}$, Hsu MC. Social support as a moderator between depressive symptoms and quality of life outcomes of breast cancer survivors. Eur J Oncol Nurs. 2013; 17: 767-74. doi:10.1016/ j.ejon.2013.03.011.

28. Panayiotou G, Karekla M. Perceived social support helps, but does not buffer the negative impact of anxiety disorders on quality of life and perceived stress. Soc Psychiatry Psychiatr Epidemiol. 2013; 48: 283-94. doi: 10.1007/s00127-012-0533-6.

29. Cohen S, Wills TA. Stress, social support, and the buffering hypothesis. Psychol Bull. 1985; 98: 31057. doi:10.1037/0033-2909.98.2.310

30. Zung WW. The measurement of affects: depression and anxiety. Mod Probl Pharmacopsychiatry. 1974; 7: 170-88. doi: 10.1159/000395075.

31. Zung WW. How normal is anxiety? Upjohn: Durham. 1980.

32. Zung WW. From art to science. The diagnosis and treatment of depression. Arch Gen Psychiatry. 1973; 29: 328-37. doi: 10.1001/archpsyc.1973.04200030026004.

33. Cella DF, Tulsky DS, Gray G, Sarafian B, Linn E, Bonomi A, et al. The Functional Assessment of Cancer Therapy scale: development and validation of the general measure. J Clin Oncol. 1993; 11: 570-9. doi:10.1200/JC0.1993. 11.3.570.

34. Zimet GD, Dahlem NM, Zimet SG, Farley GK. The Multidimensional Scale of Perceived Social Support. Journal of Personality Assessment. 1988; 52: 30-41. doi:10.1207/s15327752 jpa5201_2.

35. Andersson T, Alfredsson L, Källberg H, Zdravkovic S, Ahlbom A. Calculating measures of biological interaction. Eur J Epidemiol. 2005; 20: 575-9. doi: 10.1007/s10654-005-7835-x.

36. Rothman KJ, Greenland S. Modem epidemiology. 2nd eds. Philadelphia:A Wohers Kluwer Company. 1998; 329-342.

37. Rothman KJ. Epidemiology: 8n introduction. New York:Oxford University Press.2002; 168-180.

38. Hosmer DW, Lemeshow S. Confidence interval estimation of interaction. Epidemiology. 1992; 3: 4526. doi: 10.1097/00001648-199209000-00012.

39. Bolin JH. Introduction to Mediation, Moderation, and Conditional Process Analysis: A RegressionBased Approach. Journal of Educational Measurement. 2014; 51: 335-337. doi:10.11 11/jedm.12050

40. Lim JK, Cronkite R, Goldstein MK, Cheung RC. The impact of chronic hepatitis $C$ and comorbid psychiatric illnesses on health-related quality of life. J Clin Gastroenterol. 2006; 40: 528-34. doi: 10.1097/00004836-200607000-00012. 
41. Sareen J, Jacobi F, Cox BJ, Belik SL, Clara I, Stein MB. Disability and poor quality of life associated with comorbid anxiety disorders and physical conditions. Arch Intern Med. 2006; 166: 2109-16. doi: 10.1001/archinte.166.19.2109.

42. Roy-Byrne PP, Davidson KW, Kessler RC, Asmundson GJ, Goodwin RD, Kubzansky L, et al. Anxiety disorders and comorbid medical illness. Gen Hosp Psychiatry. 2008; 30: 208-25. doi:10.1016/j.genhosppsych.2007.12. 006.

43. Pinquart M, Duberstein PR. Depression and cancer mortality: a meta-analysis. Psychol Med. 2010; 40: 1797-810. doi: 10.1017/S0033291709992285.

44. Li W, Liu L, Puente JG, Li Y, Jiang X, Jin S, et al. Hypertension and health-related quality of life: an epidemiological study in patients attending hospital clinics in China. J Hypertens. 2005; 23: 1667-76. doi:10.1097/01.hjh.0000174 971.64589.39.

45. Carroll D, Phillips AC, Gale CR, Batty GD. Generalized anxiety and major depressive disorders, their comorbidity and hypertension in middle-aged men. Psychosom Med. 2010; 72: 16-9. doi: 10.1097/PSY.0b013e3181c4fca1.

46. Hamer M, Batty GD, Stamatakis E, Kivimaki M. Hypertension awareness and psychological distress. Hypertension. 2010; 56:547-50.doi:10.1161/HYPERTENSIONAHA.110.153775.

47. Green AJ, Bazata DD, Fox KM, Grandy S. Quality of Life, Depression, and Healthcare Resource Utilization among Adults with Type 2 Diabetes Mellitus and Concomitant Hypertension and Obesity: A Prospective Survey. Cardiol Res Pract. 2012; 404107. doi:10.1155/2012/ 404107.

48. Li CY. The incidence and the influencing factors of anxiety and depression in hypertensive patients. Bering: Beijing University of Chinese Medicine. 2013.

49. Balcı Şengül MC, Kaya V, Şen CA, Kaya K. Association between suicidal ideation and behavior, and depression, anxiety, and perceived social support in cancer patients. Med Sci Monit. 2014; 20: 32936. doi: 10.12659/MSM.889989.

50. Kobayashi R, Ishizaki M. Relationship Between Health Literacy and Social Support and the Quality of Life in Patients With Cancer: Questionnaire Study. J Particip Med. 2020; 12: e17163. doi: 10.2196/17163.

51. Kim MK, Sim JA, Yun YH, Bae DS, Nam JH, Park CT, et al. Health-Related Quality of Life and Sociodemographic Characteristics as Prognostic Indicators of Long-term Survival in Disease-Free Cervical Cancer Survivors. Int J Gynecol Cancer. 2016; 26: 743-9. doi:

10.1097/IGC.0000000000000665.

52. Carpenter KM, Fowler JM, Maxwell GL, Andersen BL. Direct and buffering effects of social support among gynecologic cancer survivors. Ann Behav Med. 2010; 39: 79-90. doi:10.1007/ s12160-0109160-1.

53. Lau Y, Wong DF, Wang Y, Kwong DH, Wang Y. The roles of social support in helping chinese women with antenatal depressive and anxiety symptoms cope with perceived stress. Arch Psychiatr Nurs. 2014; 28: 305-13. doi: 10.1016/j.apnu.2014.05.009. 
54. Vodermaier A, Linden W. Social support buffers against anxiety and depressive symptoms in patients with cancer only if support is wanted: a large sample replication. Support Care Cancer. 2019; 27: 2345-2347. doi: 10.1007/s00520-019-04737-w.

55. Schroevers MJ, Helgeson VS, Sanderman R, Ranchor AV. Type of social support matters for prediction of posttraumatic growth among cancer survivors. Psychooncology. 2010; 19: 46-53. doi: 10.1002/pon.1501.

Figures
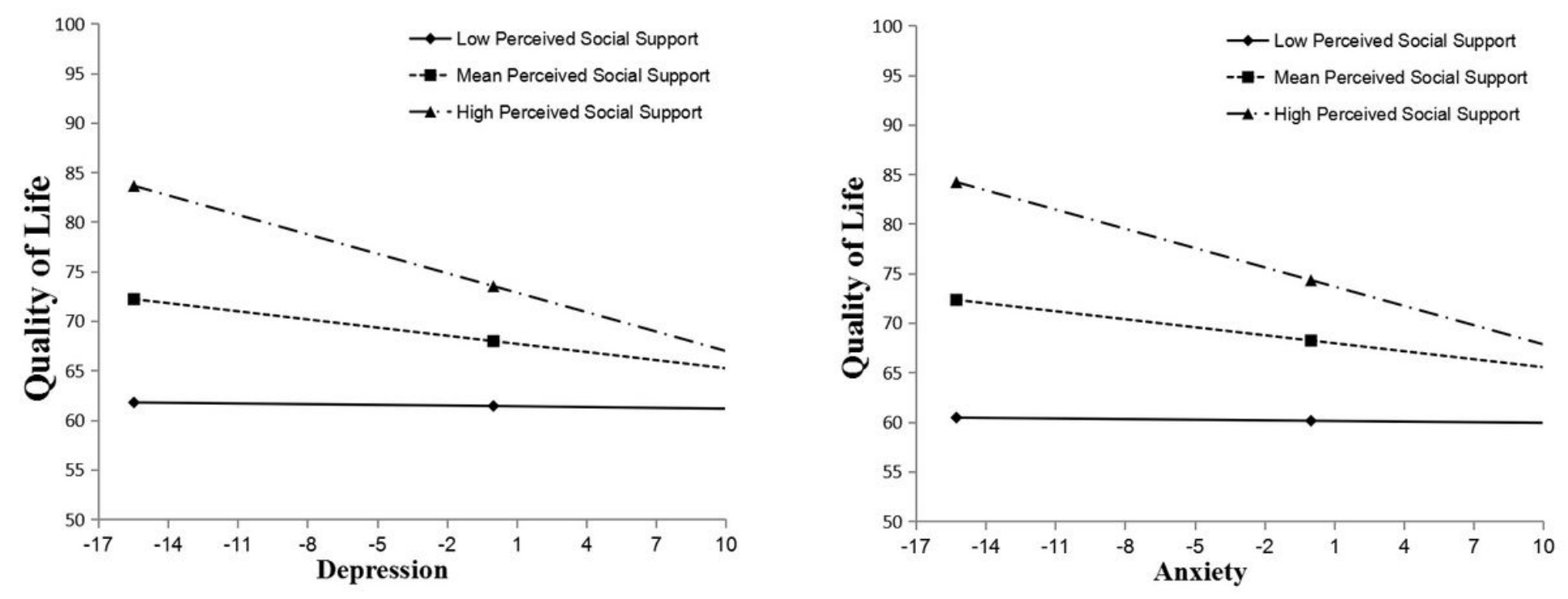

Figure 1

Simple slope plot of interaction between depression/anxiety and perceived social support on quality of life. Notes: Low, -1SD below the mean; High, +1SD above the mean. 